\title{
Epilepsy in Punjab (India): A Population-Based Epidemiologic Study
}

\author{
Harbag S. Hara ${ }^{a}$ Ajay Gupta ${ }^{b}$ Mukhtiar Singh ${ }^{a}$ Rajnish Raj ${ }^{c}$ \\ Harminder Singh ${ }^{g}$ Gaurav Pawar ${ }^{g}$ Pritam K. Hara ${ }^{\text {e, }}$ Jaswinder Singh $^{d}$ \\ Departments of a Neurology, ${ }^{b}$ Medicine, ${ }^{c}$ Psychiatry, ${ }^{d}$ Pharmacy and e College of Nursing, Government Medical \\ College and Rajindra Hospital, ${ }^{f}$ Gian Sagar College of Nursing, Ram Nagar, Banur, and ${ }^{g}$ Amar Hospital, Patiala, \\ Punjab, India
}

\section{Key Words}

Prevalence · Incidence · Classification scheme for epilepsy .

Electro-clinical syndromes

\begin{abstract}
Aims: To assess the prevalence of epilepsy in a rural area adjoining a city. Methods: A door-to-door, cross-sectional epidemiological survey was carried out covering an entire rural population of 103,693 people. Results: Crude period and point prevalence rates for active epilepsy were 7.67 and 7.44 per 1,000 respectively. Crude incidence rate was 60.76 per 100,000 during the year 2007. Mean, SD, median and variance were $17.2,16,13$ and 257.6 years respectively for age at onset of active epilepsy patients. The overall prevalence patterns among males and females were not significantly different. Active epilepsy cases $(n=795)$ included electro-clinical syndromes and constellations ( $n=117,14.7 \%$ ), symptomatic epilepsy ( $n=153,19.2 \%$ ), epilepsy due to unknown cause $(n=513,64.5 \%)$ and dual diagnosis $(n=12,1.5 \%)$. Conclusions: The present study showed that the prevalence rate, in the rural area adjoining a city, was comparable to that of the urban area and significantly less than that of the remote rural area as described by another study. Age- and sexspecific prevalence and incidence rates were similar to the
\end{abstract}

rates reported by other studies. The reason for a lower number of symptomatic cases to be reported, per this study, may be due to lack of neuroimaging.

(c) 2015 S. Karger AG, Basel

\section{Introduction}

Approximately 37 million individuals across the globe suffer from epilepsy and it is estimated that more than $80 \%$ of them live in developing countries [1]. Epilepsy has negative implications not only for the one affected by it but also for all those who are related to the affected individual [2].

Indo-Gangetic Plains are spread over many countries of South East Asia and have similar climate, soil and cropping patterns. Various studies from this region have covered a population of 4,636 [3], 8,595 [4], 20,966 [5], 24,130 [6], 30,000 [7] and 36,595 [8]. However, these studies cannot be considered totally authentic because of the following reasons: small population sizes (vide supra), lack of focus on epilepsy $[4,8]$, non-involvement of neurologists $[3,4,8]$, non-identification of study population [8] and information received was only from some key informants [7]. Instruments used in these studies [3-8] were not avail-

\section{KARGER 125}

(c) 2015 S. Karger AG, Base

0251-5350/15/0454-0273\$39.50/0

E-Mail karger@karger.com

www.karger.com/ned
Dr. Harbag Singh Hara, Associate Professor

Department of Neurology

Government Medical College and Rajindra Hospital

Sangrur Road, Patiala, Punjab 147001 (India)

E-Mail harbagdr@yahoo.co.in 


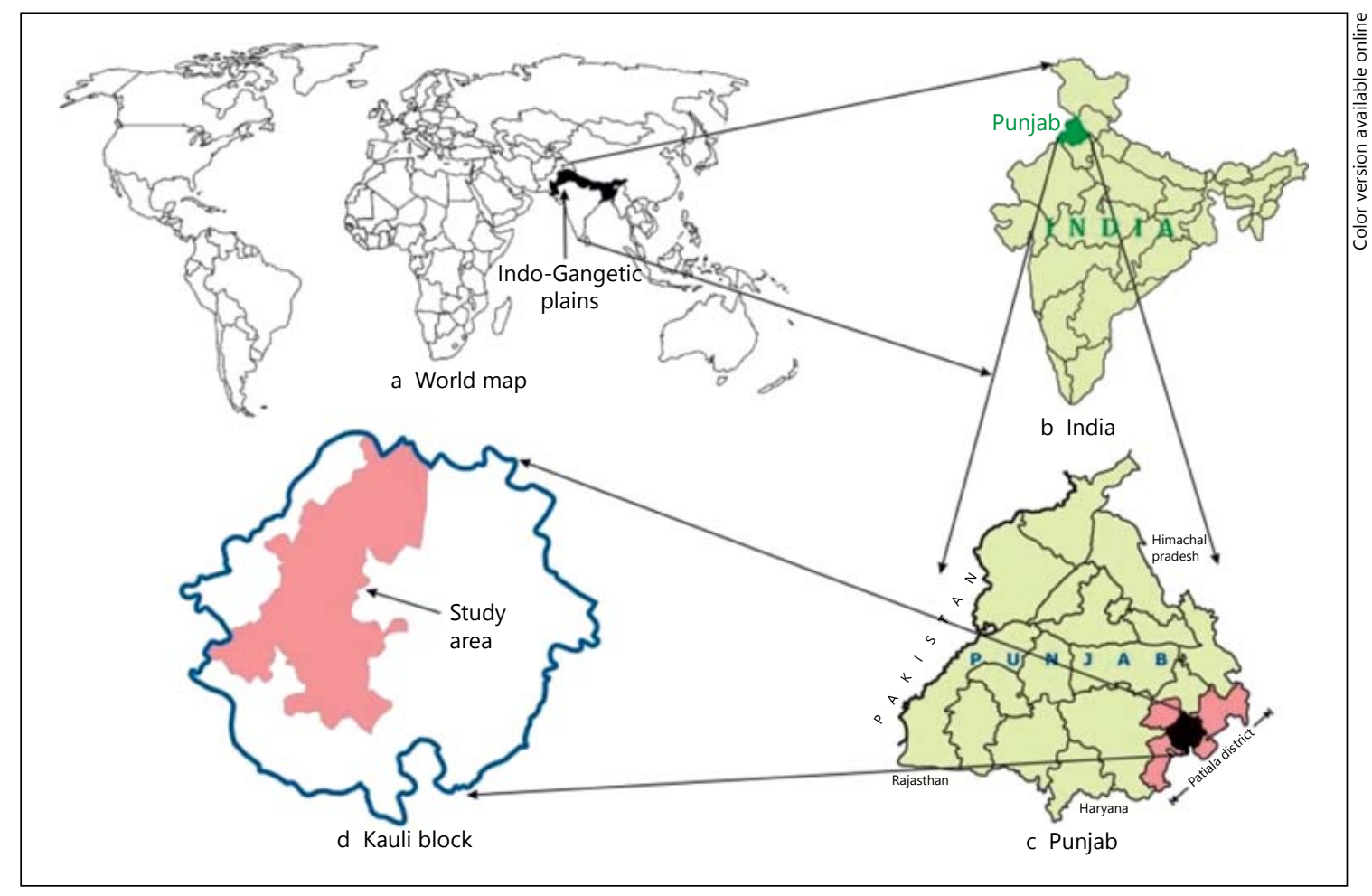

Fig. 1. Location map of study area - Kauli Block (Patiala, Punjab, India).

able for scrutiny. A prevalence rate of 3.17 (95\% CI 2.563.7) [8], lower than the usually agreed range of $4-10$ [9] and 5.33 (95\% CI 4.25-6.41) [10], was observed in the district where this study was conducted. A significantly higher prevalence was observed in the remote rural area (situated $80 \mathrm{~km}$ away from the city) as compared to the urban counterpart [6].

We performed a door-to-door survey of all the houses, covering approximately 100,000 rural population, adjoining a city, to address the above deficiencies, reassess the earlier lower prevalence in the same district and further clarify the rural-urban difference. In addition, sociopersonal aspects and health resources utilization were also assessed. Furthermore, a knowledge, attitude and practice survey was performed.

This article explains in detail the prevalence, incidence and major categories of epilepsy. The various other aspects will be reported separately.

\section{Methods}

Study Area

Patiala District is situated in East Punjab, India, in the NorthWestern part of the Indo-Gangetic Plains. It is situated at $30^{\circ} 19^{\prime} 36^{\prime} \mathrm{N}$ and $76^{\circ} 24^{\prime} 1^{\prime} \mathrm{E}$. According to the 2001 census, it had a total population of $1,844,934(987,390(53.5 \%)$ males and 857,544 (46.5\%) females), rural population of $1,200,224$ (65\%), literacy rate of $65.5 \%$ (males) and $55.2 \%$ (females), and paved road approach to 1,053 villages (99.9\%) [11]. 24.3, 20.4, 12.1 and $43.2 \%$ houses had pit, water closet type, another type and no latrine respectively in Punjab [11]. Birth, death, infant mortality and maternal mortality rates in Patiala district were 21.04, 6.07, 38.4 and 1.7 respectively [12]. The per capita income of Punjab was 39860 INR (927 USD approximately) during 2006-2007 [13].

The study area, adjoining the municipal limits of Patiala city, consisted of 74 contiguous villages (approximately $8 \%$ of the total rural population of Patiala district; fig. 1).

\section{The Survey Team}

The team included 2 neurologists, postgraduates (Internal Medicine and Psychiatry), medical graduates and paramedical staff (nursing postgraduate and pharmacist) each and the village level field workers (Anganwadi Workers (AWs) and the private health workers).

\section{The Preparatory Phase}

In July 2007, preparation of a detailed survey plan and a classification scheme (online suppl. annexure 1; for all online suppl. material, see www.karger.com/doi/10.1159/000438509), suitable for resource poor conditions, based on various related publications [14-23] was followed by a training workshop, held by the neurologists, for the doctors and the paramedical staff. After these 3 instruments, consisting of 2 separate performas (in vernacular language) 
to be filled by the AWs (for all families during the door to door survey) and by the private health workers (only for the persons having symptoms mentioned in the proforma filled by the AWs) during the screening phase and a booklet for detailed evaluation of epilepsy cases (to be filled by medical postgraduates for persons suspected to have epilepsy in the second performa) during the evaluation phase, were evolved after reviewing relevant publications [24-27] (online suppl. annexure 2, 3, 4). The proformas, after validation by 2 senior neurologists, were tested in a pilot survey carried out in field conditions (Civil Hospital and Rural Dispensary) and at the Neurology Clinic of Government Medical College and Rajendra Hospital Patiala during September 2007. Two neurologists evaluated patients in the aforementioned settings and diagnosed epilepsy in 200 patients and ruled out epilepsy in another 200 patients. The medical graduates filled the first and the second proformas for these 400 patients without knowing the diagnosis of neurologists. The sensitivity and specificity for detection of epilepsy was 96.9 and $77.9 \%$ (first proforma) and 98.4 and $80.2 \%$ (second proforma). The study was propagated through radio, television, posters, leaflets, newspapers and meetings of community leaders during November-December 2007. The clearance for the study was obtained from the Ethical Committee of the institute.

\section{The Actual Survey}

The actual survey was started in January 2008. The study area was divided into 4 clusters, each comprising 15-20 villages. One medical graduate or a paramedical staff was given the primary responsibility of coordination and record keeping for 1 cluster. The postgraduates held standardized 4-hour training sessions for field workers in each cluster. In each cluster, the field workers, after their training, carried out the screening phase. This was followed by the evaluation and the final case identification phases undertaken by the medical postgraduates and the neurologists respectively. Informed consent was obtained from the participants. The investigations, available at the time of interview, were evaluated. The medical graduates and the paramedical staff made 3-4 visits in a week to coordinate, supervise and randomly countercheck the screening phase. The postgraduate doctors and the neurologists evaluated 15-20 patients during their weekly visits. The team travelled 10-40 km during 1 visit. The survey was completed in December 2008.

\section{Statistical Methods}

A direct method of standardization was used for performing age and age-sex standardization. WHO World Standard Population [28] and 2001 Indian Census [29] were used as standards for age and age-sex standardization respectively.

Chi squares ( $\mathrm{p}<0.05)$, CIs, means, SDs, medians and variances were calculated. The maximum rates were calculated after considering the sensitivity of the performas.

\section{Results}

Details of the survey data are given in the form of a flowchart (fig. 2). Population distribution and the number of males and females in various age groups in the study area are given in online supplementary support- ing figures 1 and 2 respectively. Prevalence rates as observed by this study are given in table 1 . The prevalence of active epilepsy among males and females according to this study was similar except in the 5-9 $(\mathrm{p}=0.006)$ and $45-49$ ( $\mathrm{p}=0.008$ ) year age groups (online suppl. supporting table 1). Age and age-sex specific active epilepsy prevalence rates are depicted in online supplementary supporting figure 3 and figure 3 respectively. In this study, the mean age at onset, fell in the second decade (table 2). The crude incidence rates over 4 years are given in table 3 . Age-specific incidence rates are depicted in figure 4 .

Major categories of epilepsy are shown in table 4. All the cases with dual diagnosis had at least one symptomatic condition (online suppl. supporting table 2).

Precipitating factors were reported as none in $78.5 \%$, anxiety and fever in $5.5 \%$ each, sleep deprivation in $3.9 \%$, photic stimulation in $1.5 \%$, and alcohol, multiple and others in $1.3 \%$ each. Another $1.3 \%$ gave no information, $52.8 \%$ had seizures both during day and night, $7 \%$ had only nocturnal seizures and $1.1 \%$ had seizures only on awakening. Seizures occurred only during day time in $36.2 \%$. Among the latter, seizures occurred only during morning hours in $0.9 \%$ and the rest $35.3 \%$ had seizures later during the day, $2.8 \%$ did not give any information. Ictal and postictal features are shown in online supplementary supporting figures 4 and 5 .

\section{Discussion}

This study has addressed some deficiencies of the earlier studies by covering a large population size, conducting a door-to-door survey of all the houses and including neurologists. It has evolved a suitable methodology and a classification scheme for field conditions with lack of investigations.

\section{Prevalence}

In this study, crude and age-adjusted (WHO Standard Population) [28] active epilepsy period prevalence (January 1, 2007-December 31, 2007) rates were 7.67 (95\% CI 7.13-8.2) and 7.39 (95\% CI 6.87-7.89), while the corresponding point prevalence (December 31, 2007) rates were 7.44 (95\% CI 6.92-7.96) and 7.18 (95\% CI $6.68-7.68)$ per 1,000 respectively.

Some studies $[3,4]$ showed similar prevalence rates. Other studies $[7,8,10,21,30,31]$ showed lower prevalence (online suppl. supporting table 3 ). The lower preva- 


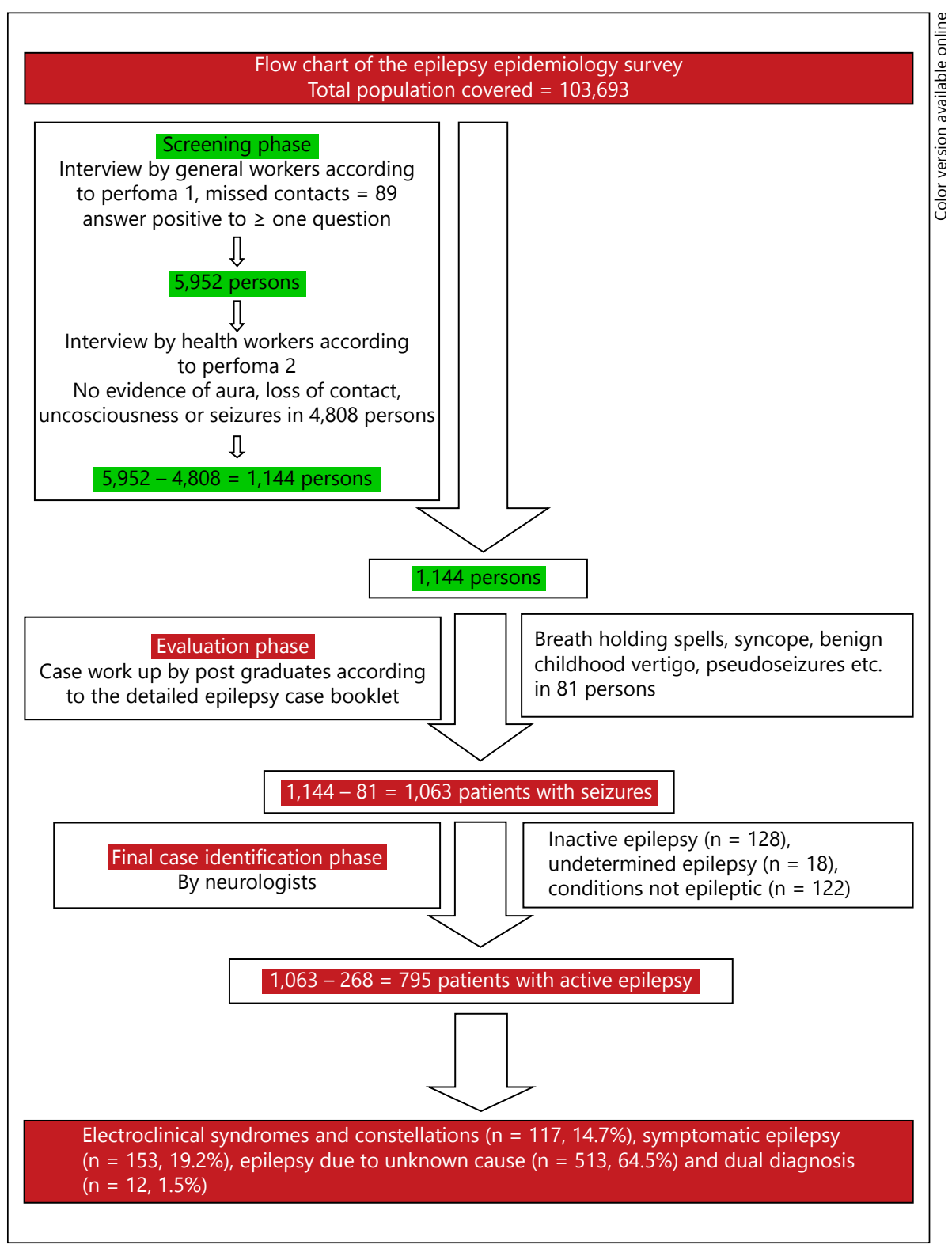

Fig. 2. Flowchart of survey data.

lence possibly occurred due to lack of focus on epilepsy [8] and survey based on key informants [7]. Alternatively, increase in population since the earlier study [8], may have caused a higher prevalence in the present study due to resulting overcrowding and poor sanitation leading to increased prevalence of neurocysticercosis [4]. The lower prevalence in areas $[21,30,31]$ outside the Indo-Gangetic Plains may be due to geographic factors. The higher prevalence $(9.99,95 \%$ CI $8.63-11.25)$ in a study [6] was due to very high prevalence $(14.8,95 \%$ CI $12.22-17.38)$ in the remote rural area. The area covered under this study and the urban counterpart of the previous study [6] have comparable (lower) prevalence $(7.44,95 \%$ CI 6.92-7.96 (present study) and 7.4, 95\% CI 6.01-8.71 [6]) and have easy access to health care facilities. Urban/rural differences have been attributed to the lack of health care infrastructure and poor hygienic living conditions [32].

\section{Incidence}

This study showed a crude incidence rate of 60.76 (95\% CI 45.75-75.76) per 100,000 in 2007. Increased incidence in 0-4 years as compared to 5-9 years and 10-14 years age groups, in this study, was possibly due to perinatal insults (fig. 4). Other studies [5, 30, 33, 34] 
Fig. 3. Age- and sex-specific active epilepsy

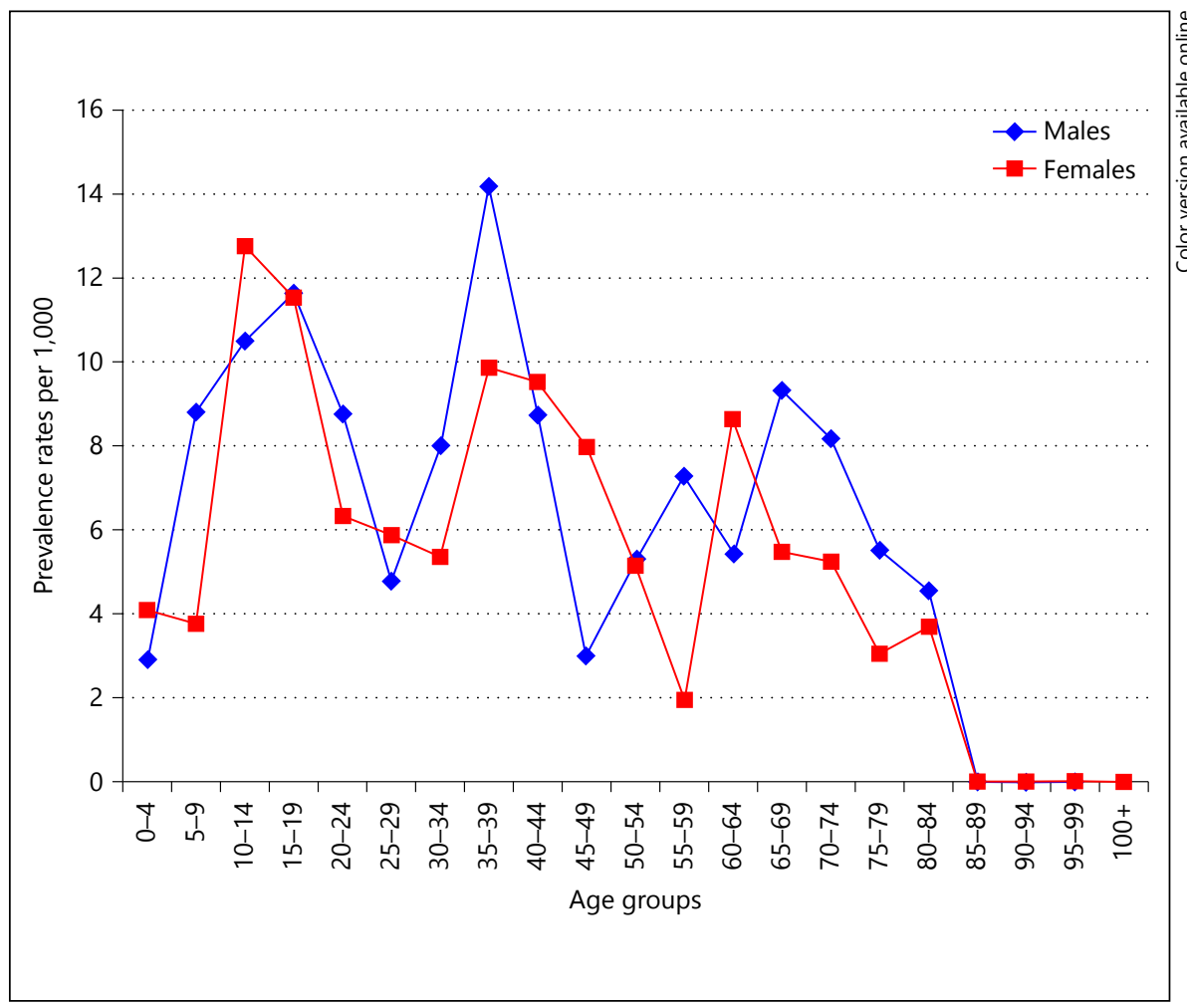
prevalence rates.

Table 1. Prevalence rates per 1,000 in the present study (population 103,693)

\begin{tabular}{lcrrr}
\hline Category & Rate & $95 \%$ CI & SE & Cases \\
\hline Crude prevalence rates per 1,000 & & & \\
Active epilepsy & $7.67^{\mathrm{a}}$ & $7.13-8.2$ & 0.27 & 795 \\
Inactive epilepsy & 1.23 & $1.01-1.44$ & 0.11 & 128 \\
Undetermined epilepsy & 0.17 & $0.09-0.25$ & 0.04 & 18 \\
Life-time prevalence of all types of epilepsy & 9.07 & $8.49-9.65$ & 0.29 & 941 \\
Conditions not epileptic & 1.18 & $0.97-1.38$ & 0.11 & 122 \\
Life-time prevalence of all types of seizures & 10.25 & $9.63-10.87$ & 0.31 & 1,063 \\
\hline
\end{tabular}

Age adjusted prevalence rates per 1,000 (WHO World Standard Population based on world average population between 2000-2025)

Active epilepsy

$7.39^{\mathrm{a}}$

$6.87-7.89$

$0.26 \quad 795$

Inactive epilepsy

1.17

$0.97-1.37$

0.10

128

Undetermined epilepsy

0.16

8.72

ef epilepsy

1.12

$0.08-0.24$

0.04

18

Conditions not epileptic

9.84

$0.92-1.32$

0.28

941

Life-time prevalence of all types of seizures

9.25-10.43

0.30

122

Maximum crude prevalence rates per 1,000

Active epilepsy

$8.04^{\mathrm{a}}$

Inactive epilepsy

1.29

0.18

$1.06-1.50$

0.28

$0.10-0.26$

9.52

Life-time prevalence of all types of epilepsy

1.23

Conditions not epileptic

10.75

$8.92-10.11$

$1.01-1.44$

$10.12-11.38$

0.11

0.04

0.30

0.10

1,063

Life-time prevalence of all types of seizures

${ }^{a}$ Period prevalence rates (January 1, 2007-December 31, 2007). 
Table 2. Mean, median, SD and variance of ages of patients (present study)

\begin{tabular}{lllllll}
\hline Category & Mean $^{\mathrm{a}}$ & $\begin{array}{l}\text { Mean } \\
\text { males }^{\mathrm{a}}\end{array}$ & $\begin{array}{l}\text { Mean } \\
\text { females }\end{array}$ & SD $^{\mathrm{a}}$ & Median $^{\mathrm{a}}$ Variance $^{\mathrm{a}}$ \\
\hline Age at the time of the survey (active epilepsy cases) & 27.88 & 27.33 & 28.57 & 17.39 & 24 & 302.43 \\
Age at onset (active epilepsy cases) & 17.22 & 16.71 & 17.87 & 16.05 & 13 & 257.57 \\
Age at onset (all seizure cases) & 15.78 & 14.96 & 17 & 15.46 & 11 & 239.16 \\
\hline
\end{tabular}

${ }^{a}$ Years. Calculations have been based on 795 active epilepsy cases included in period prevalence.

Table 3. Crude incidence rates in the present study

\begin{tabular}{lllllr}
\hline Year & $\begin{array}{l}\text { Incidence rate } \\
\text { (per 100,000) }\end{array}$ & $95 \%$ CI & SE & Cases & Population \\
\hline 2004 & 57.26 & $42.26-72.25$ & 7.65 & 56 & 97,805 \\
2005 & 74.16 & $57.26-91.06$ & 8.62 & 74 & 99,784 \\
2006 & 68.82 & $52.70-84.94$ & 8.22 & 70 & 101,720 \\
2007 & 60.76 & $45.75-75.76$ & 7.65 & 63 & 103,693 \\
\hline
\end{tabular}

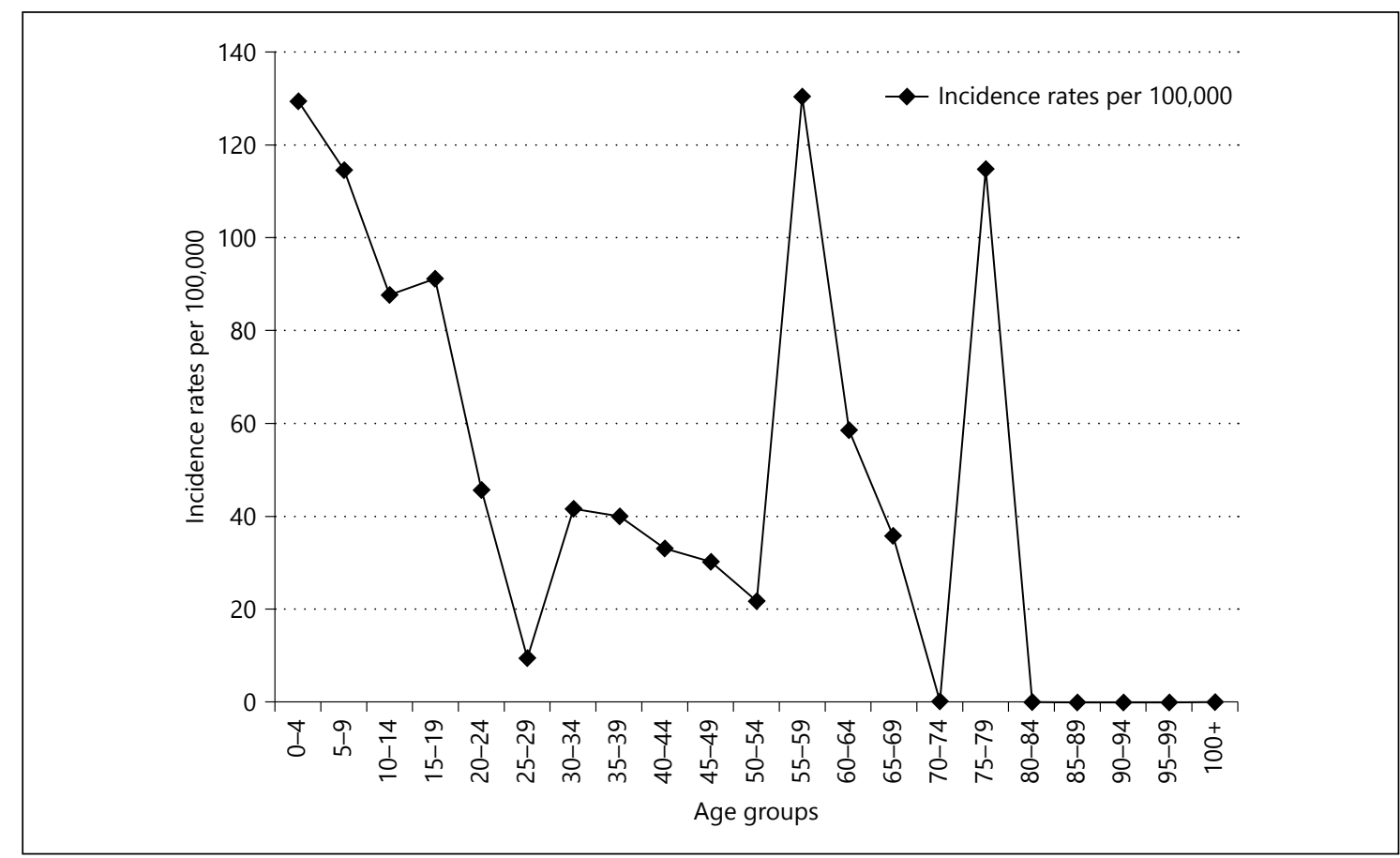

Fig. 4. Age-specific incidence rates.

revealed comparable rates (online suppl. supporting table 4). Most studies find an incidence rate of 20-70 per 100,000 [35]. Higher incidence was seen in $0-19$ and $40-49$ [5], 0-4 and $>70$ [33] and 0-29 and $>60$ [34] year age groups (online suppl. supporting table 5). Higher rates in childhood were presumably due to birth and developmental abnormalities and in older age groups due to toxic (alcoholic), vascular disease and brain tumor [33]. 
Table 4. Major categories of epilepsy

\begin{tabular}{lc}
\hline Category & Cases, n (\%) \\
\hline Electro-clinical syndromes and constellations & $117(14.7)$ \\
Symptomatic epilepsies & $153(19.2)$ \\
Epilepsy due to unknown causes & $513(64.5)$ \\
Dual diagnosis & $12(1.5)$ \\
\hline Total & 795 \\
\hline Electro-clinical syndromes and constellations & \\
Idiopathic generalized epilepsies & $111(94.9)\left(117^{*}\right)$ \\
Hemiconvulsion hemiplegia syndrome & $2(1.7)$ \\
West syndrome & $2(1.7)$ \\
Benign childhood epilepsy & $1(0.8)$ \\
Progressive myoclonic epilepsy & $1(0.8)$ \\
\hline Total & $117\left(123^{*}\right)$ \\
\hline Idiopathic generalized epilepsies & \\
Juvenile myoclonic epilepsy & $42(37.8)\left(44^{*}\right)$ \\
Idiopathic generalized epilepsies unspecified & $29(26.1)\left(31^{*}\right)$ \\
Photosensitive epilepsy & $14(12.6)$ \\
Febrile seizures plus & $10(9)\left(12^{*}\right)$ \\
Impairment of sensorium only & $9(8.1)$ \\
Juvenile absence epilepsy & $7(6.3)$ \\
\hline Total & $111\left(117^{*}\right)$ \\
\hline \multirow{2}{*}{$*$ Including cases with dual diagnosis. } & \\
\hline & \\
\hline
\end{tabular}

Sex-specific incidence rates of the present study (males (59.44, 95\% CI 39.16-79.71), females $(62.28$, 95\% CI 39.99-84.56)) were comparable to those reported by other studies $[5,33,34]$ (online suppl. supporting table 6).

\section{Age and Sex}

In this study, the mean age at onset, was 17.2 years (males (16.7), females (17.9)). It showed peaks in age-specific prevalence rate in second, fourth and seventh decades of life. The mean ages in other studies were 13.3 [6], (males (5.3), females (7.1)) [31] and 12.9 [32] years. The lower mean age may be due to variation in demographic structure. People with age less than 14 years comprised $25 \%$ in this study and approximately $40 \%$ in other studies $[6,31]$. Various studies showed peaks in age-specific prevalence rate in the second $[21,30,36-38]$, third $[6,34]$, sixth [30,34] and ninth [30] decades of life (online suppl. supporting table 7). Crude sex-specific prevalence rates of this study (males (8, 95\% CI 7.25-8.74), females (7.29, 95\% CI 6.52-8.05)) were comparable to those reported by other studies $[4,6,7,10,21,34,39]$ with 2 exceptions [37, 38] (online suppl. supporting table 8).

Epilepsy in Punjab (India)

\section{Major Categories of Epilepsy}

The classification scheme of this study is based on the latest International League Against Epilepsy (ILAE) Commission report [24]. In this study, electro-clinical syndromes and constellations, symptomatic epilepsies, epilepsy due to unknown causes and cases with dual diagnosis comprised 14.7, 19.2, 64.5 and 1.5\% respectively of the total active cases (table 4). A satisfactory comparison among studies could not be made due to lack of uniform criteria. This study reported the presence of myoclonus and absences in $81(10.2 \%)$ and $17(2.1 \%)$ patients. Other studies $[6,31,32,39]$ showed lower figures for myoclonus. Lower $[6,31]$ and higher $[32,37,39]$ number of absence cases were reported in various studies. A higher number of cases with myoclonus in this study may be due to sensitization of participating personnel during the training workshops. The screening tools for absences need to be enhanced $[36,37]$.

Other studies [5, 6, 32, 34, 36, 37, 39] showed a higher number of symptomatic cases. A lower number of symptomatic cases, as reported in this study, may be due to lack of neuroimaging (available in only $29.9 \%$ cases) because it may result in misclassification of symptomatic cases as idiopathic [37]. Neuroimaging was not done in a majority of cases possibly due to economic reasons.

\section{Limitations}

Illiterate people (39.6\%) may not be able to report the precise timing of seizure occurrence. This imprecision is likely to affect a majority of cases and hence may balance itself to some extent. Incidence data have not been derived from a prospective study but from a cross-sectional and retrospective survey.

People in rural areas hide the diagnosis of epilepsy due to the stigma attached to it. AWs are aware of the various health problems of the people because they regularly visit them and have a good rapport with them. Hence, fewer cases were missed out because even those, who feared the stigma attached to this condition, revealed the presence of epilepsy to AWs.

Poverty was another main reason for a large majority of patients not getting investigated; hence, this study predominantly relied on clinical data for categorization.

\section{Conclusions}

This study showed that the prevalence rate, in the rural area adjoining a city, was comparable to the urban area and was significantly less than the remote rural area 
according to another study. The earlier lower prevalence in the same district was erroneous, possibly due to methodological deficiencies. Age- and sex-specific prevalence and incidence rates were similar to other studies. Lower number of symptomatic cases, as observed in this study, may be due to lack of neuroimaging.

Future studies, focused to determine the causes of higher prevalence in the remote rural areas, are required to evolve strategies in order to reduce the burden of epilepsy there.
None of the authors has any conflict of interest to disclose.

We confirm that we have read the Journal's position on issues involved in ethical publication and affirm that this report is consistent with those guidelines.

\section{Funding}

Financial resources for this study were raised through voluntary contribution from the participating medical and paramedical personnel.

\section{References}

1 Leonardi M, Ustun TB: The global burden of epilepsy. Epilepsia 2002;43(suppl 6):21-25.

2 Ellis N, Upton D, Thompson P: Epilepsy and the family: a review of current literature. Seizure 2000;9:22-30.

3 Nepal MK, Sharma VD, Shrestha PM: Epilepsy prevalence, a case study of Morang District. International workshop on epilepsy conducted jointly by epilepsy care in developing countries (EPICADEC) and Department of Psychiatry, Institute of Medicine. Kathmandu, Nepal, April 15, 1996, pp 1723.

4 Kokkat AJ, Verma AK: Prevalence of seizures and paralysis in a rural community. J Indian Med Assoc 1998;96:43-45.

5 Saha SP, Bhattachrya S, Roy BK, Basu A, Roy T, Maity B, Das SK: A prospective incidence study of epilepsy in a rural community of West-Bengal, India. Neurology Asia 2008;13: 41-48.

6 Aziz H, Ali SM, Frances P, Khan MI, Hasan KZ: Epilepsy in Pakistan: a population-based epidemiologic study. Epilepsia 1994;35:950958.

7 Singh A, Kaur A: Epilepsy in rural Haryana prevalence and treatment seeking behaviour. J Indian Med Assoc 1997;95:37-39, 47.

8 Shah B, Parhee R, Kumar N, Khanna T, Singh R: Mental Health Research in India. Technical Monograph on ICMR Mental Health Studies. Indian Council of Medical Research, New Delhi, 2005. http://www.icmr.nic.in/publ/ mental\%20helth\%20.pdf (accessed December 1, 2013).

9 Sander JW, Shorvon SD: Epidemiology of the epilepsies. J Neurol Neurosurg Psychiatry 1996;61:433-443.

10 Sridharan R, Murthy BN: Prevalence and pattern of epilepsy in India. Epilepsia 1999;40: 631-636.

11 Census of India, 2001: Office of the Registrar General \& Census Commissioner, India, New Delhi. http://www.censusindia.gov.in/2011common/Census DataSummary.html (accessed December 1, 2013).
12 District Health Profile, 2008: Office of the Deputy Commissioner, Patiala. http://patiala. nic.in/html/district_health_menu.htm (accessed December 1, 2013).

13 Statistical Reports: Per capita/Gross State Domestic Product 2006-2007, Annexure VI B, Department of Planning, Punjab Government, Chandigarh. http://pbplanning.gov.in/ archives.htm (accessed December 1, 2013).

14 Guidelines for epidemiologic studies on epilepsy. Commission on epidemiology and prognosis, International League Against Epilepsy. Epilepsia 1993;34:592-596.

15 ILAE Commission Report: The epidemiology of the epilepsies: future directions. International League Against Epilepsy. Epilepsia 1997;38:614-618.

16 Engel J Jr; International League Against Epilepsy (ILAE): A proposed diagnostic scheme for people with epileptic seizures and with epilepsy: report of the ILAE task force on classification and terminology. Epilepsia 2001;42: 796-803.

17 Blume WT, Lüders HO, Mizrahi E, Tassinari C, van Emde Boas W, Engel J Jr: Glossary of descriptive terminology for ictal semiology: report of the ILAE task force on classification and terminology. Epilepsia 2001;42:1212-1218.

18 Engel J Jr: Report of the ILAE classification core group. Epilepsia 2006;47:1558-1568.

19 Fisher RS: Editor's introduction: cabbages and kings in the classification of seizures and the epilepsies. Epilepsia 2003;44:1-13.

20 Berg AT, Berkovic SF, Brodie MJ, Buchhalter J, Cross JH, van Emde Boas W, Engel J, French J, Glauser TA, Mathern GW, Moshé SL, Nordli D, Plouin P, Scheffer IE: Revised terminology and concepts for organization of seizures and epilepsies: report of the ILAE commission on classification and terminology, 20052009. Epilepsia 2010;51:676-685.

21 Radhakrishnan K, Pandian JD, Santhoshkumar T, Thomas SV, Deetha TD, Sarma PS, Jayachandran D, Mohamed E: Prevalence, knowledge, attitude, and practice of epilepsy in Kerala, South India. Epilepsia 2000;41:1027-1035.
22 Proposal for revised classification of epilepsies and epileptic syndromes. Commission on Classification and Terminology of the International League Against Epilepsy. Epilepsia 1989;30:389-399.

23 Proposal for revised clinical and electroencephalographic classification of epileptic seizures. From the Commission on Classification and Terminology of the International League Against Epilepsy. Epilepsia 1981;22:489-501.

24 World Health Organization: Development of Strategies for Community - Based Neuropsychiatric Services: Report of an Intercountry Consultation Bangkok, Thailand, 19-22 November 2002. Regional Office for SouthEast Asia, New Delhi, June 2002.

25 World Health Organization: Training Manual for Community - Based Health Workers on Identification and Care of Generalized TonicClonic Seizures (Major Fits). Regional Office for South - East Asia, New Delhi, October 2004.

26 Anand K, Jain S, Paul E, Srivastava A, Sahariah SA, Kapoor SK: Development of a validated clinical case definition of generalized tonic - clonic seizures for use by community - based health care providers. Epilepsia 2005;46:743-750.

27 Gourie-Devi M, Gururaj G, Satishchandra P, Subbakrishna DK: Prevalence of neurological disorders in Bangalore, India: a communitybased study with a comparison between urban and rural areas. Neuroepidemiology 2004;23:261-268.

28 Ahmad O, Boschi-Pinto C, Lopez AD, Murray $\mathrm{CJL}$, Lozano $\mathrm{R}$, Inoue $\mathrm{M}$ : Age Standardization of Rates: A New WHO Standard. GPE Discussion Paper Series No. 31. Geneva, World Health Organization, 2001.

29 Census of India, 2001: Population Projections for India and States 2001-2026. Report of the Technical Group on Populations Projections Constituted by the National Commission on Population. Office of the Registrar General and Census Commissioner, India, New Delhi, 2006. 
30 Mani KS, Rangan G, Srinivas HV, Kalyanasundaram S, Narendran S, Reddy AK: The Yelandur study: a community - based approach to epilepsy in rural South India - epidemiological aspects. Seizure 1998; 7:281-288.

31 Koul R, Razdan S, Motta A: Prevalence and pattern of epilepsy (Lath/Mirgi/Laran) in rural Kashmir, India. Epilepsia 1988;29:116122.

32 Aziz H, Güvener A, Akhtar SW, Hasan KZ: Comparative epidemiology of epilepsy in Pakistan and Turkey: population-based studies using identical protocols. Epilepsia 1997; 38:716-722.
33 Kurland LT: The incidence and prevalence of convulsive seizures in a small urban community. Epilepsia 1959/1960;1:143-161.

34 Rwiza HT, Kilonzo GP, Haule J, Matuja WB, Mteza I, Mbena P, Kilima PM, Mwaluko G, Mwang'ombola R, Mwaijande F, et al: Prevalence and incidence of epilepsy in Ulanga, a rural Tanzanian district: a community-based study. Epilepsia 1992;33:1051-1056.

35 World Health Organization: Epilepsy in the Western Pacific Region: A Call to Action: Global Campaign Against Epilepsy. Regional Office for the Western Pacific, Manila, 2004.
36 Attia-Romdhane N, Mrabet A, Ben Hamida M: Prevalence of epilepsy in Kelibia, Tunisia. Epilepsia 1993;34:1028-1032.

37 Al Rajeh S, Awada A, Bademosi O, Ogunniyi A: The prevalence of epilepsy and other seizure disorders in an Arab population: a community based study. Seizure 2001;10:410-414.

38 Bielen I, Cvitanovic-Sojat L, Bergman-Markovic B, Kosicek M, Planjar-Prvan M, Vuksic L, Miketek G, Matek P: Prevalence of epilepsy in Croatia: a population-based survey. Acta Neurol Scand 2007;116:361-367.

39 Hauser WA, Annegers JF, Kurland LT: Prevalence of epilepsy in Rochester, Minnesota: 1940-1980. Epilepsia 1991;32:429-445. 